\title{
Urgences
}

\section{A contre-jour (photos de Michèle Lavoie)}

\section{Jean Cossette}

Numéro 7, 2e trimestre 1983

URI : https://id.erudit.org/iderudit/025103ar

DOI : https://doi.org/10.7202/025103ar

Aller au sommaire du numéro

Éditeur(s)

Urgences

ISSN

0226-9554 (imprimé)

1927-3924 (numérique)

Découvrir la revue

Citer ce document

Cossette, J. (1983). A contre-jour (photos de Michèle Lavoie). Urgences, (7),

33-44. https://doi.org/10.7202/025103ar d'utilisation que vous pouvez consulter en ligne.

https://apropos.erudit.org/fr/usagers/politique-dutilisation/ 


\section{JEAN COSSETTE}

\section{A contre-jour}

(photos: Michèle Lavoie) 


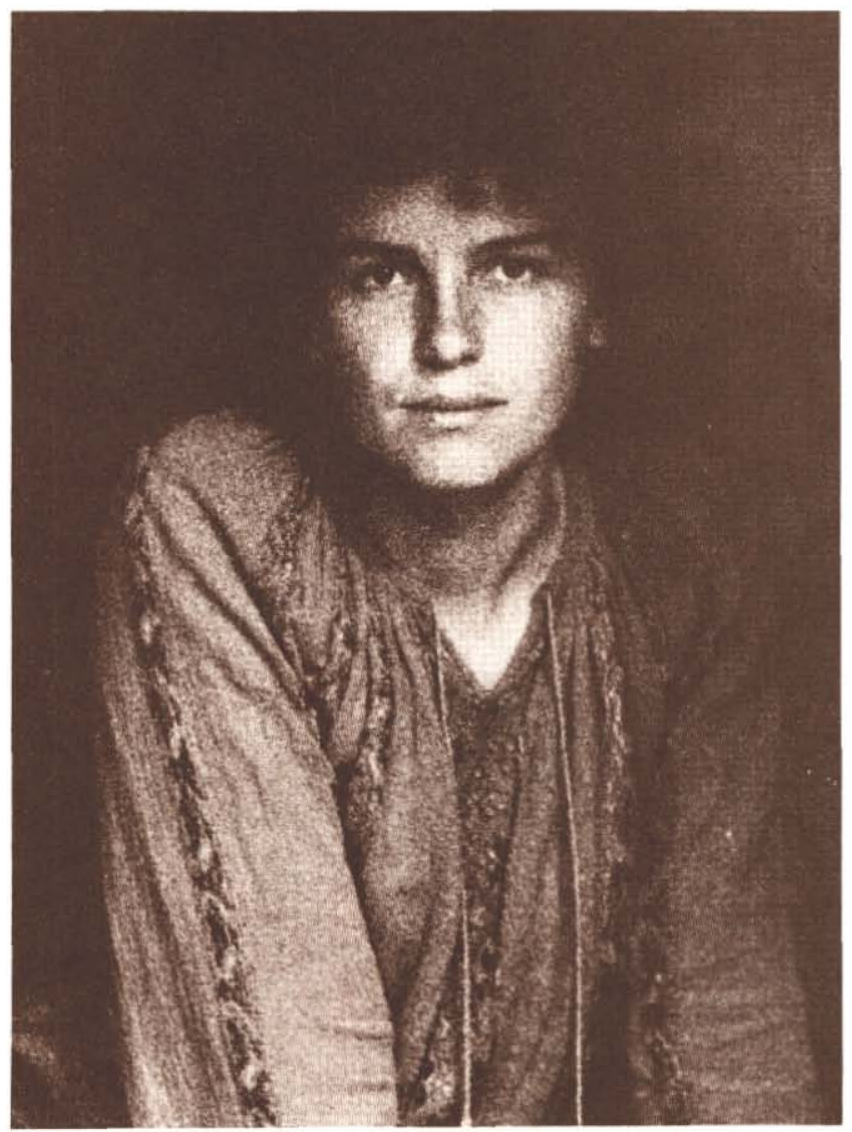

Comme nous vivons à contre-jour 


\section{À CONTRE-JOUR}

Comme je te mange sans avoir faim sans comprendre I'humeur cachée Comme je te hante du bout des yeux ignorant ce que ta main fredonne dans le vide comatique des autres en lambeaux ou en voyage névrotique

Comme je tends à l'infini chaos

dans le sperme que je fabrique inconsciemment pour t'envoyer dans les rêves qui ne t'appartiennent plus pour te chercher des voiles de mystère en l'absence du néant imagé dans les soubresauts de nos corps emmêlés alors que veillent nos naissances lointaines et nos rencontres brèves à I'heure des automnes maritimes où des pays que nous ne verrons jamais ne serait-ce que pour revivre des joies multiformes 
Comme j'aspire ta moelle pendant que nos doigts jouent du mélo sous une lune vieille jadis pleine de nos secrets et maintenant dehors avec les chiens d'hiver

Comme je n'ose plus te dire: merveille... car les mots ne véhiculent plus que du vent alors que nous partons vers des cimes vierges sans chercher à comprendre l'immense tourment qui nous accable

Comme nous vivons à contre-jour laissant dormir les gestes

le mortel diffamatoire des sens

Comme nous renaissons

semblables à des lucioles de nulle part. 


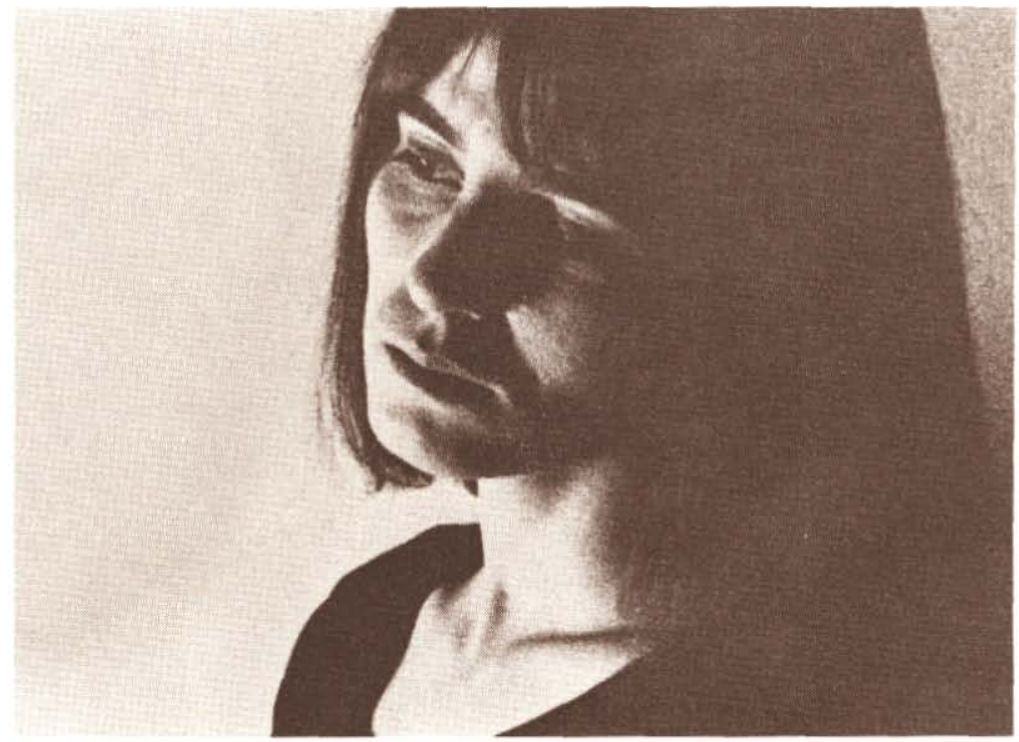

dans la soif nocturne des désespérés en mal d'aube 


\section{ESSAIM}

Dans les sous-bois du silence

à I'heure basse des mélancolies-charnières

les fougères de l'esprit s'acharnent à rire...

Comme si on pouvait oublier

la douleur des consciences malmenées!

Enfermer une fois pour toutes

l'essaim démesuré des attentes vaines

dans la soif nocturne des désespérés en mal d'aube et crier, par le dedans, à longueur de semaines, l'étrange voilier des bonheurs passagers

quand le verbe se fait amant d'illusion

et catalyseur de songes bénéfiques. 


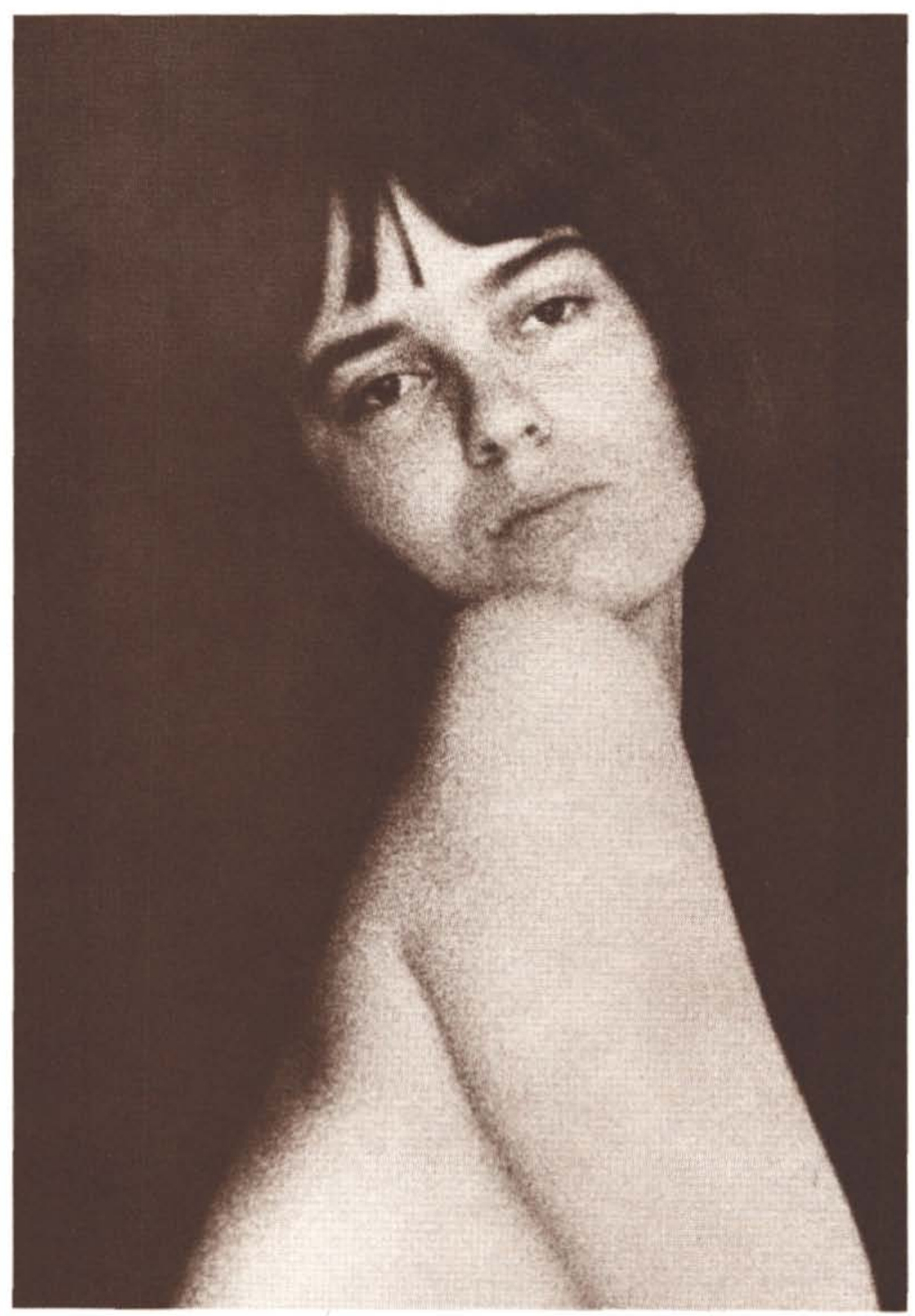

Ta langue ne dort plus que par la fixité des gisants 


\section{DE BRIBES EN FROIDURE}

Le temps s'émerveille encore d'être le seul à connaître le très profond des heures sans gloire

La vie qui ne tient qu'à ton fil s'effiloche peu à peu au portique de l'angoisse et tu inventes des mystères sublimes où s'accroupissent des chameaux éventrés

Ta langue ne dort plus que par la fixité des gisants

Le froid n'habite plus que nous

Mes mains dorment déjà du sommeil calfeutré des indolores

A qui d'autre s'en prendre qu'à la lueur mensongère des bougies à bout de souffle. 
Le droit de s'en aller reste en sursis en nos chambres secrètes Ce vague ennui de m'entendre briser des hivers contre les parois démesurées de l'attente

Ce souffle retenu qui déchire les entrailles de mes silences suffocants et l'espace restreint, dépressif, du songe avorté en mon antre de granite.

Ces yeux qui ne cessent d'entendre la raison des rescapés aux masques de cire

M'en voudras-tu de boucler le visage de l'inutile et d'en faire un passé de pierre...

Faudra-t-il retenir les larmes aigres de la solitude face au miroir aigu de ces retours incessants vers l'autre versant de nousmême... 


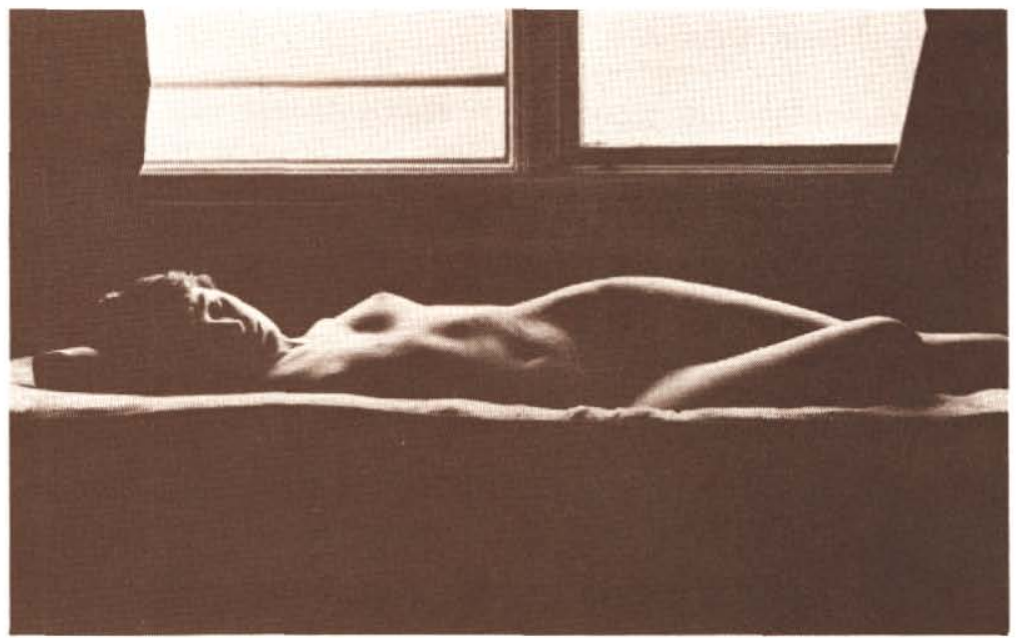

De grisaille en blafard en transparence muette 


\section{VISION PALPABLE}

La terre coule en méandres sépia entre les rives du grand lit de neige bordées de carillons ciselés

De grisaille en blafard en transparence muette, tout le ciel repose au creux de toi, tandis que la caresse de ta main à ta cuisse dilue à mon regard tapi dans l'ombre, des musiques semblables à quelques nuages mystérieux venus du dedans de moi

Peu à peu l'ombre a regagné l'ombre et le cheval au sang chaud a repris de ses courses cramoisies au fin fond de mon imagerie secrète

Du retour libertin de mes souvenirs rompus j'ai comme dans la chair un tressaillement serein très long et venu bien au-delà des nuits polaires là où l'ardente folie des hommes se meut encore dans le paradis orgiaque bleu rouge jaune en primaires filamenteuses

sur les fonds clairs-obscurs du désir 


\begin{abstract}
A l'instant où tu poses le regard sur le mien déjà couché en toi, tous les champagnes ambrés de ta chambre remontent en bulles sonores au plafond de nos joies vertébrales, et dès lors, nos enveloppes radicales tombent bien en dessous de nous, pour laisser filtrer nos intérieurs lucides comme des mouettes chevauchant les mers d'été
\end{abstract}

Dans nos hivers de glace on a laissé fondre un peu de notre chair transparente juste assez pour irriguer la sécheresse qui nous rongeait depuis des siècles

A force de se donner la vie à bras-le-corps et sans attendre d'autres sommeils peut-être mon amie verrons-nous poindre à l'orée de nos horizons superposés le grand soleil qui se languissait dans les profondeurs de ce lac indigo que l'on croyait désert. 